\title{
Splanchnic Metabolism of Plasma Apolipoprotein B
}

\author{
STUDIES OF ARTERY-HEPATIC VEIN DIFFERENCES OF MASS AND \\ RADIOLABEL IN FASTED HUMAN SUBJECTS
}

\author{
P. R. Turner, N. E. Miller, C. Cortese, W. Hazzard, J. Coltart, and \\ B. Lewis, Department of Chemical Pathology and Metabolic Disorders \\ and Department of Cardiology, St. Thomas' Hospital Medical School, London, \\ SE1 7EH England
}

A B S T RACT The metabolism of apoprotein B-containing plasma lipoproteins by human splanchnic tissues has been studied in 29 men undergoing coronary angiography. Before catheterization autologous radioiodinated lipoproteins were infused into a peripheral vein: 10 subjects received ${ }^{125}$ I-labeled Sf $12-60$ lipoproteins; 12 received ${ }^{125}$ I-labeled Sf $12-60$ plus ${ }^{131} \mathrm{I}-$ labeled Sf $100-400$ lipoproteins; and 7 received ${ }^{125} \mathrm{I}$ labeled Sf 12-60 plus ${ }^{131}$ I-labeled Sf 0-12 lipoproteins. Paired arterial and hepatic vein blood samples were subsequently collected for replicate measurements of apoprotein B (apo B) mass, radioactivity and specific activity in each lipoprotein class. Splanchnic plasma flow was measured with indocyanine green. All studies were conducted after a 14-h overnight fast.

Newly synthesized apo B was shown to be secreted by splanchnic tissues as a component of $S f$ 100-400 lipoproteins, with no detectable uptake of apo $B$ from this class. Sf 12-60 apo B was extracted by the splanchnic bed, with no detectable secretion. After continuous intravenous infusion of ${ }^{125}$ I-labeled Sf $12-60$ for five or more hours, $41-67 \%$ (mean 55\%) of extracted Sf 12-60 apo $B$ radioactivity reappeared in hepatic vein Sf 0-12 apo $B$. There was no detectable splanchnic catabolism of Sf 0-12 apo B.

The rates of Sf 100-400 apo B secretion, calculated as the product of artery-hepatic vein concentration difference and splanchnic plasma flow, were greater than the previously reported rates of very low density lipopro-

This work was presented in part at the Annual Meeting of the European Society for Clinical Investigation, Cambridge, England, April 1979, and at the Fifth International Symposium on Atherosclerosis, Houston, Tex., November 1979.

Dr. Hazzard was an Investigator of the Howard Hughes Medical Institute, and was supported by a grant from the American Egg Board. Address reprint requests to Dr. Lewis.

Received for publication 28 May 1980 and in revised form 11 February 1981. tein apo B turnover in fed subjects obtained by kinetic analysis of plasma specific radioactivity decay curves, suggesting that there may be a diurnal variation in hepatic apo B synthesis. They also exceeded the splanchnic extraction rates of Sf 12-60 apo B, suggesting there was some extrasplanchnic catabolism of the apo B of Sf $>60$ lipoproteins.

\section{INTRODUCTION}

The kinetics of plasma very low density lipoprotein (VLDL) ${ }^{1}$ and low density lipoprotein (LDL) metabolism in man have been the subject of numerous investigations. It is now established that a precursorproduct relationship exists between VLDL-apolipoprotein B (apo B) and LDL-apo B, and that lipoproteins of intermediate density and flotation rate are intermediate in this metabolic sequence (1-4). Normally, all LDLapo $B$ is derived from VLDL-apo B (2-4), but in familial hypercholesterolemia there is evidence of LDL-apo B synthesis not involving VLDL as a precursor, in both the homozygous (5) and heterozygous (6) forms. Oversecretion of VLDL-apo B has been reported in hypertriglyceridemia $(3,7,8)$, particularly in hypertriglyceridemia due to familial combined hyperlipidemia (9). Catabolic defects may underlie other disorders characterized by elevated plasma triglyceride levels $(4,5,7,10)$.

Most studies have used preparations of autologous VLDL, LDL and/or intermediate lipoprotein classes (Sf 12-20 or Sf 12-60) labeled in vitro with radioiodine. After intravenous injection of such radiolabeled lipo-

\footnotetext{
1 Abbreviations used in this paper: Apo B, apolipoprotein B; $C_{a}$, concentration in artery; $C_{h v}$, concentration in hepatic vein; LDL, low density lipoprotein (Sf 0-12); SPF, splanchnic plasma flow; VLDL, very low density lipoprotein (Sf 20-400).
} 
proteins, sequential peripheral blood samples have been assayed for apo B specific activity in different lipoprotein fractions, and the specific activity time curves analyzed to give values for the pool sizes, production rates, interconversion and fractional rates of catabolism of the lipoproteins. Other procedures to label apo B have also been used (11). The use of apo $B$ as a marker of the metabolism of these lipoproteins appears to be particularly apt, as this protein is quantitatively conserved during the metabolism of VLDL and LDL, playing a structural role in the composition of the particles $(1,4,12)$.

Possible discrepancies exist between certain of the published accounts of VLDL-apo B metabolism in man. Though the transfer of apo $B$ from larger to smaller VLDL subclasses appears to be quantitative in normolipidemic subjects, it is unclear whether all apo $B$ is transferred to LDL. Sigurdsson et al. (2) concluded that more than $90 \%$ of VLDL-apo B is normally transferred to the Sf $0-20$ range (2), and other studies have suggested that most VLDL-apo B normally reappears in Sf 0-12 lipoproteins (4). Other investigations, however, have suggested that some apo B in VLDL, or in the Sf 12-20 range, may be catabolized by an alternative pathway $(3,5)$. The synthetic rates of VLDL-apo $B$ and LDLapo $\mathrm{B}$ are correlated, but only moderately so $(r$ $=+0.57$ ) (7), which may favor the latter interpretation. Among the possible explanations for these varying reports is the heterogeneity of the assumed models for the VLDL-to-LDL cascade, which vary in their complexity and for which there is a dearth of physiological bases.

We have sought an alternative approach, not dependent on model building, to define the kinetics of the metabolism of apo B-containing lipoproteins in man. By making measurements of apo $B$ mass and radiolabel in different lipoprotein fractions, isolated from samples of arterial and hepatic venous blood following intravenous injection of radioiodinated autologous lipoproteins, the synthesis, interconversion and catabolism of VLDL (Sf 100-400), LDL (Sf 0-12), and intermediate density lipoproteins ( $S f$ 12-60) in the human splanchnic bed have been directly quantified. An analogous approach has been employed by Havel et al. (13) and Boberg et al. (14) for the measurement of splanchnic triglyceride secretion, and more recently by Sniderman et al. (15) to study LDL cholesterol metabolism by the splanchnic viscera.

A further objective of the study concerned the localization of various steps in the VLDL-to-LDL cascade. The paucity of information on regional lipoprotein metabolism in man contrasts with the wealth of animal data obtained, for example, by use of isolated perfused livers $(16,17)$, functional hepatectomy $(18,19)$, multiple indwelling catheters (20), and measurement of organ distribution of ${ }^{125}$ I following injection of labeled lipoproteins (21).

\section{METHODS}

Subjects. 29 male patients were selected at random from those undergoing routine cardiac catheterization for suspected myocardial ischemia in St. Thomas' Hospital. Ages ranged from 26 to $68 \mathrm{yr}$, plasma cholesterol concentration from 5.0 to $8.3 \mathrm{mmol} / \mathrm{liter}$, and plasma triglyceride from 0.90 to 5.60 mmol/liter. No patient had clinical or biochemical evidence of diabetes mellitus, alcoholism, renal disease, or liver disease. One patient (No. 16) was taking thyroxine for myxoedema; five had been taking lipid-lowering drugs (subject 13, cholestyramine; subjects $1,22,23$, and 29, clofibrate), but these were withdrawn $3 \mathrm{~d}$ before catheterization. The majority of the patients were taking adrenergic beta-blocking agents for angina pectoris. Although some of these have been reported to produce small changes in plasma lipids, they were continued for ethical reasons. The clinical details of each patient are given in Table $I$. All were hospitalized 4-6 d before catheterization, and remained on an isocaloric solid diet (derived calories: 45, 40, 15; carbohydrate, fat, protein). Body weights remained essentially constant. Coronary angiography demonstrated normal arteries in three patients, and single, double, or triple vessel disease in the remainder.

Preparation of radioiodinated autologous lipoproteins. Peripheral venous blood $(150 \mathrm{ml})$ was collected after a $14-\mathrm{h}$ overnight fast, using disodium EDTA $(1 \mathrm{mg} / \mathrm{ml})$ as anticoagulant, and plasma was immediately separated by centrifugation at $4^{\circ} \mathrm{C}$. When present, chylomicrons ( $\mathrm{Sf}>400$ ), were removed by aspiration after overlayering plasma with $\mathrm{NaCl}$ solution of $d=1.006 \mathrm{~g} / \mathrm{ml}$ and centrifugation at $20,000 \mathrm{~g}$ for 20 min (23). Subsequently lipoproteins of Sf 100-400, Sf 12-60 and Sf 0-12 were isolated by sequential preparative ultracentrifugation at $4^{\circ} \mathrm{C}$ in an MSE Prepspin 50 centrifuge, according to previously described procedures $(23,24)$; an MSE 900 rotor (MSE Scientific Instruments, Sussex, England) was used.

$4 \mathrm{vol}$ of plasma were overlayered with $2 \mathrm{vol}$ of $d 1.006 \mathrm{~g} / \mathrm{ml}$ solution, and centrifuged at $87,000 \mathrm{~g}$ for $50 \mathrm{~min}$ (24). The supernatant lipoproteins ( $\mathrm{Sf}$ 100-400) were removed by aspiration, and concentration by recentrifugation under similar conditions. The infranate was mixed and 4 vol again overlayered with $2 \mathrm{vol}$ of $d 1.006 \mathrm{~g} / \mathrm{ml}$ solution. After centrifugation at $105,000 \mathrm{~g}$ for $110 \mathrm{~min}$, the supernatant lipoproteins (Sf 60-100) were aspirated and discarded. After mixing the infranate, 5 vol were added to $1 \mathrm{vol}$ of $d 1.085 \mathrm{~g} / \mathrm{ml}$ solution (to give a final $d$ of $1.019 \mathrm{~g} / \mathrm{ml}$ ) and centrifuged at $105,000 \mathrm{~g}$ for $20 \mathrm{~h}$. The supernatant lipoproteins (Sf 12-60, $d$ 1.006-1.019 g/ml) were removed and concentrated by recentrifugation at $1.019 \mathrm{~g} / \mathrm{ml}$. Lipoproteins of $d$ 1.019-1.063 $\mathrm{g} / \mathrm{ml}$ (Sf 0-12) were then isolated by ultracentrifugation at $105,000 \mathrm{~g}$ for $20 \mathrm{~h}$, after addition of $2 \mathrm{vol}$ of $d 1.151 \mathrm{~g} / \mathrm{ml}$ solution to $4 \mathrm{vol}$ of the $d 1.019 \mathrm{~g} / \mathrm{ml}$ infranate, and concentrated by recentrifugation at $1.063 \mathrm{~g} / \mathrm{ml}$.

The lipoprotein fractions were dialyzed against $0.15 \mathrm{M} \mathrm{NaCl}$ (pH 7.4) at $4^{\circ} \mathrm{C}$ before labeling. Sf $100-400$ or Sf 0-12 lipoproteins were labeled with ${ }^{131} I$, and Sf $12-60$ with ${ }^{125} I$, using the iodine monochloride method of McFarlane (25) as modified by Langer et al. (26).

Assuming a molecular weight of 300,000 for total VLDL apolipoprotein (4) and 100,000 for LDL apolipoprotein (2), a maximum of one iodine atom was incorporated per molecule of protein. Free iodide was partially removed from the preparation by passage through a column of Sephadex G-10 $(20 \times 0.5 \mathrm{~cm})$. Sterile human serum albumin was added to the eluted lipoprotein (final concentration, $5 \% \mathrm{wt} / \mathrm{vol}$ ) to minimize auto-irradiation damage. Residual free iodide was removed by dialysis against $0.15 \mathrm{M} \mathrm{NaCl}-1 \mathrm{mg} / \mathrm{dl} \mathrm{Na}_{2} \mathrm{EDTA}$ (pH 7.4). The labeled lipoproteins were then made up to $10 \mathrm{ml}$ with $0.15 \mathrm{M} \mathrm{NaCl}$ and passed through a $0.45-\mu \mathrm{m}$ filter (Millipore Corp., Bedford, Mass.). 
TABLE I

Clinical Details of Patients Studied

\begin{tabular}{|c|c|c|c|c|c|c|c|c|c|c|}
\hline $\begin{array}{l}\text { Study } \\
\text { No. }\end{array}$ & Weight & Height & Age & $\begin{array}{c}\text { Plasma } \\
\text { cholesterol }\end{array}$ & $\begin{array}{c}\text { Plasma } \\
\text { tri- } \\
\text { glyceride }\end{array}$ & $\begin{array}{l}\text { VLDL } \\
\text { tri- } \\
\text { glyceride }\end{array}$ & $\begin{array}{l}\text { LDL } \\
\text { cholesterol }\end{array}$ & $\begin{array}{l}\text { Lipoprotein } \\
\text { phenotype* }\end{array}$ & $\begin{array}{c}\text { Study } \\
\text { protocolf }\end{array}$ & Drug therapy \\
\hline & $k g$ & $\mathrm{~cm}$ & $y r$ & \multicolumn{4}{|c|}{ mmol/liter } & & & \\
\hline 1 & 74 & 172 & 38 & 5.0 & 0.90 & 0.6 & 3.1 & IV\$ & 1 & Propranolol, clofibrate \\
\hline 2 & 82 & 166 & 49 & 5.3 & 2.2 & 1.4 & 3.7 & Normal & 1 & Verapamil, salbutamol \\
\hline 3 & 79 & 183 & 40 & 6.9 & 4.8 & 3.2 & 4.3 & IV & 1 & Propranolol \\
\hline 4 & 72 & 170 & 58 & 6.5 & 1.5 & 0.9 & 4.6 & Normal & 1 & $\begin{array}{l}\text { Ibuprofen, nitrazepam, } \\
\text { metoprolol }\end{array}$ \\
\hline 5 & 93 & 184 & 52 & 6.2 & 2.3 & 1.8 & 4.1 & Normal & 1 & Propranolol, diazepam \\
\hline 6 & 78 & 175 & 68 & 6.0 & 1.7 & 0.9 & 4.1 & Normal & 1 & $\begin{array}{l}\text { Acebutalol, diazepam, } \\
\text { glyceryl trinitrate }\end{array}$ \\
\hline 7 & 80 & 179 & 58 & 5.7 & 2.0 & 1.3 & 4.1 & Normal & 1 & Metoprolol, diazepam \\
\hline 8 & 56 & 164 & 63 & 8.0 & 5.6 & 4.6 & 6.2 & IIb & 1 & Prednisone, metoprolol \\
\hline 9 & 77 & 173 & 48 & 6.7 & 1.8 & 1.1 & 3.8 & Normal & 1 & None \\
\hline 10 & 81 & 169 & 57 & 5.2 & 2.3 & 1.5 & 3.8 & Normal & 1 & Propranolol \\
\hline 11 & 71 & 168 & 44 & 8.0 & 4.1 & 3.5 & 6.0 & IIb & 1 & $\begin{array}{l}\text { Propranolol, perhexiline, } \\
\text { nifedipine, bendro- } \\
\text { fluazide }\end{array}$ \\
\hline 12 & 70 & 177 & 26 & 5.2 & 2.0 & 1.5 & 3.4 & Normal & 1 & None \\
\hline 13 & 73 & 173 & 42 & 6.6 & 2.6 & 1.8 & 5.0 & IIb & 2 & $\begin{array}{l}\text { Propranolol, cholestyra- } \\
\text { mine, nifedipine }\end{array}$ \\
\hline 14 & 75 & 183 & 34 & 8.1 & 2.1 & 1.3 & 6.6 & IIa & 2 & None \\
\hline 15 & 76 & 179 & 58 & 6.7 & 0.9 & 0.4 & 4.7 & Normal & 2 & $\begin{array}{l}\text { Nifedipine, sprinolactone, } \\
\text { metoprolol, digoxin }\end{array}$ \\
\hline 16 & 73 & 170 & 49 & 7.4 & 2.7 & 2.0 & 4.9 & IIb & 2 & Thyroxine, bendrofluazide \\
\hline 17 & 73 & 168 & 37 & 7.3 & 4.5 & 3.6 & 4.9 & IIb & 2 & Glyceryl trinitrate \\
\hline 18 & 84 & 171 & 46 & 6.4 & 2.9 & 2.2 & 4.5 & IV & 2 & Propranolol \\
\hline 19 & 90 & 178 & 45 & 5.9 & 2.0 & 1.4 & 4.1 & Normal & 2 & $\begin{array}{l}\text { Propranolol, nifidipine, } \\
\text { sorbide nitrate }\end{array}$ \\
\hline 20 & 79 & 181 & 59 & 7.4 & 2.1 & 1.3 & 5.4 & IIa & 3 & $\begin{array}{l}\text { Propranolol, oxacepam, } \\
\text { glyceryl trinitrate }\end{array}$ \\
\hline 21 & 68 & 174 & 49 & 5.6 & 2.3 & 1.4 & 3.8 & Normal & 3 & $\begin{array}{l}\text { Metoprolol, chlorthali- } \\
\text { done }\end{array}$ \\
\hline 22 & 74 & 171 & 43 & 7.7 & 3.3 & 2.1 & 4.8 & III" & 3 & Propranolol, clofibrate \\
\hline 23 & 77 & 173 & 49 & 8.3 & 3.2 & 2.3 & 6.5 & IIb & 3 & Propranolol, clofibrate \\
\hline 24 & 74 & 180 & 52 & 4.6 & 1.0 & 0.5 & 3.4 & Normal & 3 & Digoxin, frusemide \\
\hline 25 & 65 & 163 & 57 & 6.3 & 2.0 & 1.1 & 4.4 & Normal & 3 & Sotalol, sorbide nitrate \\
\hline 26 & 82 & 182 & 36 & 8.3 & 1.4 & 0.8 & 5.7 & IIa & 3 & Chlorpromazine \\
\hline 27 & 70 & 170 & 44 & 6.2 & 2.8 & 2.2 & 4.3 & Normal & 3 & Propranolol \\
\hline 28 & 65 & 165 & 65 & 7.9 & 1.8 & 1.2 & 6.0 & IIa & 3 & Acebutalol \\
\hline 29 & 87 & 180 & 36 & 6.6 & 2.7 & 2.1 & 3.6 & III" & 3 & $\begin{array}{l}\text { Clofibrate, atenolol, } \\
\text { isosorbide dinitrate }\end{array}$ \\
\hline
\end{tabular}

* Beaumont et al. (22).

† Radiolabeled lipoprotein(s) injected or infused: $1,{ }^{131} \mathrm{I}-\mathrm{Sf}>100$ and ${ }^{125} \mathrm{I}-\mathrm{Sf} 12-60 ; 2,{ }^{125} \mathrm{I}-\mathrm{Sf} 12-60$ and ${ }^{131} \mathrm{I}-\mathrm{Sf} 0-12 ; 3,{ }^{125} \mathrm{I}-\mathrm{Sf} 12-60$ alone. In studies 23-28 blood was sampled from the inferior vena cava as well as from the hepatic vein.

$\S$ Plasma lipoproteins normalized during clofibrate therapy.

" Broad $\beta$ band demonstrated on agarose gel electrophoresis of $d<1.006 \mathrm{~g} / \mathrm{ml}$ lipoproteins.

Less than $4 \%$ of the radioactivity in the final preparations was present as free iodide, as determined by precipitation with $15 \%$ trichloroacetic acid $\left(10 \mathrm{~min}, 21^{\circ} \mathrm{C}\right)$. The percentage of radiolabel in the lipid moiety averaged $4.5 \%$ in Sf $100-400$, $4.7 \%$ in Sf $12-60$, and $3.0 \%$ in Sf $0-12$ lipoproteins, as determined by solvent extraction according to Scanu and Edelstein (27).

All procedures were carried out using sterile glassware. In- organic aqueous solutions were made up in pyrogen-free distilled water, sterilized by autoclaving, and stored at $4^{\circ} \mathrm{C}$. Cellulose nitrate ultracentrifuge tubes were sterilized with $\mathbf{7 0 \%}$ isopropanol, and all lipoprotein manipulations were conducted, whenever possible, in a laminar flow cabinet.

Clinical procedures. The studies were carried out in patients undergoing routine cardiac catheterization in the course of investigation for suspected coronary heart disease. Elec- 
tive studies for purely research purposes were not undertaken. The nature of the investigation was discussed with all patients, each of whom gave informed consent.

Each patient received $50 \mathrm{mg}$ potassium iodide orally each morning from the day of admission until $3 \mathrm{~d}$ after catheterization, to minimize thyroidal uptake of radioiodine. Catheterization studies were conducted in the morning after a 14-h overnight fast.

Intravenous reinjection of radioiodinated lipoproteins was performed within $96 \mathrm{~h}$ of the initial blood collection. Three different protocols were used: (a) Bolus injection (in $0.15 \mathrm{M}$ $\mathrm{NaCl}$ ) of ${ }^{131}$ I-labeled Sf $100-400$ plus ${ }^{125}$ I-labeled Sf $12-60$ lipoproteins (10-30 $\mu \mathrm{Ci}$ of each), followed by catheterization 40-60 min later (12 patients). ( $b$ ) Bolus injection of ${ }^{125}$ I-labeled Sf $12-60$ plus ${ }^{131}$ I-labeled Sf $0-12$ lipoproteins $(10-30 \mu \mathrm{Ci}$ of each), followed by catheterization $1-5 \mathrm{~h}$ later (seven patients). (c) Initial bolus injection of ${ }^{125}$ I-labeled Sf $12-60(40 \mu \mathrm{Ci})$, followed by continuous intravenous infusion of this preparation at $10 \mu \mathrm{Ci} / \mathrm{h}$ for $5-22 \mathrm{~h}$ up to catheterization (10 patients). On each occasion 5-6 mg of lipoprotein protein was injected. There were no pyrogenic or allergic reactions.

The catheterization procedure involved the standard Seldinger technique (28). A No. 7 French catheter was introduced under fluoroscopic guidance into the lower right hepatic vein via the right femoral vein under local anesthesia with lignocaine. A No. 8 Pigtail catheter was introduced into the aorta as far as the origin of the celiac axis, via the right femoral artery. Indocyanine green was infused via an indwelling cannula in the left antecubital vein. Blood samples $(60 \mathrm{ml})$ were drawn simultaneously from the aorta and hepatic vein during a timed 90-s period, and divided into separate aliquots for: $(a)$ measurement of packed cell volume in triplicate; $(b)$ measurement of indocyanine green; and $(c)$ lipoprotein analyses ( $1 \mathrm{mg} \mathrm{Na} \mathrm{N}_{2} \mathrm{EDTA} / \mathrm{ml}$ ). Catheter lines were kept patent with sterile $0.15 \mathrm{M} \mathrm{NaCl}$, and no heparin was introduced until completion of the lipoprotein studies, in view of the effect of heparin in releasing lipoprotein lipase and hepatic lipase into the circulation (29). The interval between the start of the catheterization and blood sampling did not exceed $30 \mathrm{~min}$.

Splanchnic plasma flow measurement. After a bolus injection (15 mg, i.v.), indocyanine green (Cardio Green; Hynson, Westcott and Dunning Inc., Baltimore, Md.) was infused ( 0.5 $\mathrm{mg} / \mathrm{min}$ ) using a Harvard pump for at least $15 \mathrm{~min}$ before blood sampling. The concentrations of dye in arterial and hepatic venous plasma were determined spectrophotometrically at $815 \mathrm{~nm}$, using as standard curve dilutions of the dye in plasma and a plasma blank. The Fick principle was applied to calculate the splanchnic plasma flow (SPF) (30):

where,

$$
\mathrm{SPF}=\frac{\mathrm{I}}{\mathrm{C}_{\mathrm{a}}-\mathrm{C}_{\mathrm{hv}}} \text { milliliters per minute, }
$$

$I$ = infusion rate (milligrams per minute),

$\mathrm{C}_{\mathrm{a}}=$ concentration (milligrams per milliliter) in artery,

$\mathrm{C}_{\mathrm{hv}}=$ concentration (milligrams per milliliter) in hepatic vein.

Lipoprotein analyses. Because of the high blood flow through the splanchnic bed, it was assumed that arteriovenous concentration differences would be small; hence, it was considered necessary to conduct multiple replicate analyses on the arterial and hepatic venous samples in order to obtain reliable data. To this end each plasma sample was ultracentrifuged in quadruplicate, apo $B$ isolations were performed in triplicate, and apo B mass measurements were made in duplicate. Throughout the lipoprotein analyses arterial and venous samples were processed in parallel and in identical manner.

The lipoprotein fractions of Sf $100-400$, Sf $12-60$, and Sf
0-12 were isolated by sequential preparative ultracentrifugation, as already described. Mass and specific activity measurements of apo B in Sf 100-400, Sf 12-60, and Sf 0-12 lipoproteins were made by precipitation of apo B with $1,1,3,3$ tetramethylurea (Sigma Chemical Co., St. Louis, Mo.) (31) that had been redistilled in glass at $176^{\circ} \mathrm{C}$. Aliquots $(0.5 \mathrm{ml})$ of the lipoprotein fractions were mixed with $0.5 \mathrm{ml}$ tetramethylurea for $10 \mathrm{~min}$ at $25^{\circ} \mathrm{C}$. When necessary, lipoproteins were first diluted with $0.15 \mathrm{M} \mathrm{NaCl}$ to a protein concentration of $<1.5 \mathrm{mg} / \mathrm{ml}$, to ayoid coprecipitation of apoprotein $\mathrm{C}$ (31). Following centrifugation at $6,000 \mathrm{~g}$ for $20 \mathrm{~min}$ the tetramethylurea-soluble infranate was removed with a finely drawn-out Pasteur pipette. Lipid was removed from the pellet by overnight extraction in ethanol/ether $(3: 2, \mathrm{vol}: \mathrm{vol})$ at $10^{\circ} \mathrm{C}$ followed by two ether extractions. The residual apo $\mathrm{B}$ precipitate was dried and dissolved in $1 \mathrm{ml}$ of $0.5 \mathrm{M} \mathrm{NaOH}$. After radioactivity determination in an LKB (LKB Instruments, Inc. Rockville, Md.) Wallac gamma counter, the protein content was determined by the method of Lowry et al. (32), slightly modified (in that $\mathrm{NaOH}$ was admitted from the sodium carbonate reagent to compensate for the $\mathrm{NaOH}$ in which the apo B was dissolved); bovine serum albumin (Sigma Chemical Co.) was used as standard.

The mean coefficients of variation (percent) for replicate assays $(n=24)$ of apo $B$ mass $(m),{ }^{125} \mathrm{I}$ radioactivity $(\mathrm{r})$ and specific activity in the different lipoproteins were as follows; $\mathrm{Sf}$ 100-400: $\mathrm{m} 4.6, \mathrm{r} 2.5$, sp act 5.1; Sf 12-60: $\mathrm{m} \mathrm{8.4,} \mathrm{r} \mathrm{4.2,} \mathrm{sp} \mathrm{act}$ 7.7; Sf $0-12$ : $\mathrm{m} \mathrm{5.3,} \mathrm{r} 3.7$, sp act 6.0. That for replicate assays of ${ }^{131} \mathrm{I}$ radioactivity in Sf 0 - 12 was $3.7 \%$.

When ${ }^{125}$ I-labeled Sf $100-400$, ${ }^{131}$ I-labeled Sf $12-60$, or ${ }^{125} \mathrm{I}$ labeled Sf 0-12 lipoproteins were added to samples of arterial (art) and hepatic venous (hv) plasma, and the corresponding fractions reisolated according to the ultracentrifugal procedures described above, the following percentage recoveries were obtained (mean $\pm S D, n=6$ ); Sf 100-400: art 91.3 \pm 2.2 hv 90.3 \pm 2.3 ; Sf $12-60$ : art $88.3 \pm 3.8$, hv $88.0 \pm 1$.1; Sf 0-12: art $81.7 \pm 4.4$, hv $84.2 \pm 2.6$.

Values for the rate of splanchnic secretion or uptake of apo $B$ (milligrams per kilogram per hour) were calculated as: $\left(C_{h v}-C_{a}\right)$. SPF/BW, where $C_{h v}=$ mean hepatic vein apo $B$ concentration (milligrams per milliliter), $\mathrm{C}_{\mathrm{a}}=$ meän arterial apo $B$ concentration (milligrams per milliliter), SPF = splanchnic plasma flow (milliliters per hour), and BW $=$ body weight (kilograms).

\section{RESULTS}

Values obtained for splanchnic plasma flow (range, $7.7-11.8 \mathrm{ml} / \mathrm{min}$ per $\mathrm{kg}$; mean, 9.0 ) in the 19 patients (Nos. 1-19) in whom this was measured were similar to previously reported values (30). Packed cell volumes in arterial and hepatic venous blood were not significantly different $(43.8 \pm 0.6$ vs. $43.3 \pm 0.6 \%)$. Thus, none of the recorded differences in lipoprotein mass and radioactivity across the splanchnic bed was attributable to hemodilution or hemoconcentration.

Sf 100-400 lipoproteins. The artery-hepatic vein differences in apo B mass and apo B radioactivity in plasma lipoproteins of Sf 100-400 are presented in Table II. In 11 of 12 subjects the concentration of Sf 100-400 apo B was significantly higher in hepatic vein plasma than in arterial plasma. In no patient, however, was there a statistically significant artery-hepatic vein difference in Sf $100-400$ apo B radioactivity. In the 
TABLE II

Sf 100-400 Apoprotein B Mass, Radioactivity, and Specific Activity in Arterial and Hepatic Venous Plasma following Intravenous Injection of ${ }^{131}$ I-labeled Sf 100-400 Lipoproteins

\begin{tabular}{|c|c|c|c|c|c|c|}
\hline \multirow{2}{*}{$\begin{array}{c}\text { Patient } \\
\text { No. }\end{array}$} & \multicolumn{2}{|r|}{ Mass } & \multicolumn{2}{|c|}{ Radioactivity } & \multicolumn{2}{|c|}{ Specific activity } \\
\hline & Artery & Hepatic vein & Artery & Hepatic vein & Artery & Hepatic vein \\
\hline & \multicolumn{2}{|r|}{$m g / d l$} & \multicolumn{2}{|c|}{$c p m / m l$} & \multicolumn{2}{|c|}{ cpm/mg } \\
\hline 1 & $3.9 \pm 0.09$ & $4.4 \pm 0.10^{*}$ & $1,142 \pm 90$ & $1,247 \pm 40(\mathrm{NS})$ & $22,019 \pm 320$ & $21,526 \pm 473$ \\
\hline 2 & $2.8 \pm 0.12$ & $3.6 \pm 0.66 \ddagger$ & $1,120 \pm 49$ & $1,144 \pm 42$ (NS) & $40,795 \pm 4,368$ & $32,968 \pm 3,045 \ddagger$ \\
\hline 3 & $10.9 \pm 0.71$ & $12.4 \pm 0.32^{*}$ & $2,082 \pm 81$ & $2,217 \pm 82(\mathrm{NS})$ & $19,266 \pm 778$ & $17,879 \pm 566 \ddagger$ \\
\hline 4 & $9.3 \pm 0.22$ & $9.9 \pm 0.31 \ddagger$ & $3,750 \pm 64$ & $3,833 \pm 54(\mathrm{NS})$ & $40,778 \pm 1,082$ & $38,717 \pm 982 \ddagger$ \\
\hline 5 & $6.2 \pm 0.14$ & $7.5 \pm 0.09 \ddagger$ & $1,708 \pm 96$ & $1,631 \pm 70(\mathrm{NS})$ & $27,468 \pm 1,994$ & $21,221 \pm 2,698$ \\
\hline 6 & $3.2 \pm 0.17$ & $4.0 \pm 0.23 \ddagger$ & $1,467 \pm 27$ & $1,408 \pm 69(\mathrm{NS})$ & $45,794 \pm 812$ & $35,000 \pm 1,099^{*}$ \\
\hline 7 & $5.1 \pm 0.14$ & $5.5 \pm 0.17 \ddagger$ & $1,128 \pm 13$ & $1,141 \pm 21(\mathrm{NS})$ & $22,048 \pm 413$ & $20,698 \pm 385$ \\
\hline 8 & $10.5 \pm 0.20$ & $11.4 \pm 0.26^{*}$ & $354 \pm 7$ & $349 \pm 11(\mathrm{NS})$ & $3,384 \pm 150$ & $3,052 \pm 106$ \\
\hline 9 & $5.2 \pm 0.12$ & $5.9 \pm 0.14^{*}$ & $2,258 \pm 16$ & $2,254 \pm 20(\mathrm{NS})$ & $43,702 \pm 1,838$ & $37,936 \pm 2,013^{*}$ \\
\hline 10 & $6.8 \pm 0.29$ & $7.5 \pm 0.33^{*}$ & $464 \pm 18$ & $480 \pm 19$ (NS) & $6,792 \pm 93$ & $6,453 \pm 81^{*}$ \\
\hline 11 & $10.9 \pm 0.38$ & $11.6 \pm 0.47(\mathrm{NS})$ & $1,038 \pm 36$ & $1,078 \pm 85(\mathrm{NS})$ & $9,512 \pm 114$ & $9,414 \pm 174(\mathrm{NS})$ \\
\hline 12 & $6.8 \pm 0.32$ & $7.7 \pm 0.41 \downarrow$ & $896 \pm 39$ & $923 \pm 22(\mathrm{NS})$ & $13,384 \pm 968$ & $11,882 \pm 713 \ddagger$ \\
\hline
\end{tabular}

Results are given as mean \pm SEM of 24 measurements. Statistical comparisons of arterial and hepatic venous data were performed by Student's $t$ test: ${ }^{*} P<0.01 ; \square P<0.05$; NS, $P>0.05$.

pooled data from all patients there was a significant $(P<0.001)$ increase in concentration of $14.0 \pm 2.1 \%$ (mean \pm SEM) and a significant $(P<0.001)$ decrease in specific activity of $10.5 \pm 2.2 \%$ across the splanchnic organs, with no significant arteriovenous difference in apo $B$ radioactivity. These results demonstrate secretion of newly synthesized apo B in Sf 100-400 lipoproteins by splanchnic tissues, with no detectable uptake within the region of Sf $100-400$ apo B from arterial blood.

Values for the splanchnic secretion rate of Sf $100-400$ apo $B$ ranged from 1.9 to $7.0 \mathrm{mg} / \mathrm{kg}$ per $\mathrm{h}$. Results in the hypertriglyceridemic patients (Nos. 3,8 , and 11) were higher than those in the normotriglyceridemic patients (Nos. 2, 4-7, 9, 10, and 12), but this difference failed to achieve statistical significance $(6.0 \pm 0.78 \mathrm{vs}$. $4.2 \pm 0.51 \mathrm{mg} / \mathrm{kg}$ per $\mathrm{h} ; 0.05<P<0.10$ ). Patient 1 was excluded from this comparison on account of the apparent residual triglyceride-lowering effect of clofibrate (see Table I).

Sf 12-60 lipoproteins. As shown in Table III, in 20 of the 29 patients both apo B concentration and apo B radioactivity in Sf 12-60 lipoproteins were significantly lower in hepatic vein plasma than in arterial plasma. Of the remaining nine patients, three showed a statistically significant decrease across the splanchnic bed in apo $B$ concentration alone, and two others showed a significant decrease in radioactivity alone. In the pooled data, the decrease in apo $B$ concentration averaged $6.4 \pm 2.9 \%$ and that in apo $B$ radioactivity averaged $6.1 \pm 3.3 \%$. Accordingly, there was no significant change across the splanchnic bed in the specific activity of Sf 12-60 apo B. Thus, an uptake of Sf 12-60 lipopro- teins from arterial plasma was demonstrated within the splanchnic region, without any detectable secretion of newly synthesized apo B into this fraction.

Values for splanchnic removal of Sf 12-60 apo B, calculated in patients $1-19$, ranged from 0.90 to $6.3 \mathrm{mg} / \mathrm{kg}$ per $h$. Results in the hypertriglyceridemic patients (again excluding subject 1 ) did not differ significantly from those in the normotriglyceridemic patients $(2.3$ \pm 0.5 vs. $2.7 \pm 0.5 \mathrm{mg} / \mathrm{kg}$ per h).

Conversion of Sf 12-60 apo B to Sf 0-12 apo B. A proportion of the radioactivity that was extracted from the Sf 12-60 lipoproteins in the splanchnic bed was found to reappear in the apo B of the Sf 0-12 fraction of hepatic venous plasma (Table IV). In the first seven patients (Nos. 13-19), in whom this was quantified following a bolus injection of ${ }^{125}$ I-labeled Sf $12-60$, the incorporation of ${ }^{125}$ I into hepatic vein Sf 0-12 apo B (expressed as a percentage of the total radioactivity removed from Sf 12-60 apo B) appeared to depend upon the interval between injection and blood sampling, increasing from 22 to $53 \%$ as the interval was increased from 2 to $5 \mathrm{~h}$. These results are presented in Fig. 1 . Since the recovery of radiolabeled Sf 0-12 apo B from plasma was a little lower than that of radiolabeled $\mathbf{S f}$ 12-60 apo B (see Methods) these values will be slight underestimates.

These findings were explored further in patients 20-29, in whom ${ }^{125}$ I-Sf $12-60$ lipoproteins were infused continuously for 4.5 to $22 \mathrm{~h}$ prior to blood sampling. In seven normotriglyceridemic patients (Nos. 20, 21, 24-28) and one hypertriglyceridemic patient (No. 23) the percentage incorporation of extracted $S f$ 12-60 apo B radioactivity into Sf 0-12 apo B reached a plateau after 
TABLE III

Sf 12-60 Aproprotein B Mass, Radioactivity, and Specific Activity in Arterial and Hepatic Venous Plasma following Intravenous Injection of ${ }^{125}$-labeled Sf 12-60 Lipoproteins

\begin{tabular}{|c|c|c|c|c|c|c|}
\hline \multirow{2}{*}{$\begin{array}{l}\text { Patient } \\
\text { No. }\end{array}$} & \multicolumn{2}{|r|}{ Mass } & \multicolumn{2}{|c|}{ Radioactivity } & \multicolumn{2}{|c|}{ Specific activity } \\
\hline & Artery & Hepatic vein & Artery & Hepatic vein & Artery & Hepatic vein \\
\hline & \multicolumn{2}{|r|}{$m g / d l$} & \multicolumn{2}{|c|}{$c p m / m l$} & \multicolumn{2}{|c|}{ cpm/mg } \\
\hline 1 & $4.4 \pm 0.11$ & $3.9 \pm 0.23^{*}$ & $2,648 \pm 54$ & $2,544 \pm 85^{*}$ & $46,449 \pm 1,327$ & $43,632 \pm 1,876^{*}$ \\
\hline 2 & $5.2 \pm 0.27$ & $4.5 \pm 0.35^{*}$ & $2,592 \pm 145$ & $2,504 \pm 251(\mathrm{NS})$ & $51,844 \pm 698$ & $53,348 \pm 1,072(\mathrm{NS})$ \\
\hline 3 & $7.5 \pm 0.15$ & $7.7 \pm 0.18(\mathrm{NS})$ & $6,362 \pm 64$ & $6,377 \pm 90(\mathrm{NS})$ & $84,804 \pm 1,943$ & $82,629 \pm 1,881(\mathrm{NS})$ \\
\hline 4 & $6.3 \pm 0.38$ & $5.5 \pm 0.24^{*}$ & $9,605 \pm 219$ & $8,677 \pm 122^{*}$ & $153,110 \pm 2,861$ & $157,636 \pm 2,998$ (NS) \\
\hline 5 & $2.1 \pm 0.09$ & $1.8 \pm 0.08 \ddagger$ & $6,633 \pm 142$ & $6,135 \pm 78^{*}$ & $315,667 \pm 4,771$ & $335,137 \pm 3,819^{*}$ \\
\hline 6 & $6.9 \pm 0.13$ & $6.6 \pm 0.13^{*}$ & $11,009 \pm 227$ & $8,925 \pm 352^{*}$ & $159,651 \pm 3,845$ & $135,921 \pm 3,303 \ddagger$ \\
\hline 7 & $3.0 \pm 0.09$ & $2.8 \pm 0.06^{*}$ & $8,973 \pm 115$ & $8,431 \pm 96^{*}$ & $294,098 \pm 6,714$ & $301,071 \pm 7,807(\mathrm{NS})$ \\
\hline 8 & $6.2 \pm 0.19$ & $5.8 \pm 0.11^{*}$ & $3,514 \pm 56$ & $3,303 \pm 34^{*}$ & $56,850 \pm 246$ & $56,995 \pm 128(\mathrm{NS})$ \\
\hline 9 & $5.0 \pm 0.17$ & $4.6 \pm 0.21^{*}$ & $1,932 \pm 119$ & $1,791 \pm 78^{*}$ & $39,411 \pm 328$ & $39,345 \pm 514$ (NS) \\
\hline 10 & $5.2 \pm 0.14$ & $4.7 \pm 0.24^{*}$ & $2,701 \pm 76$ & $2,538 \pm 71^{*}$ & $52,237 \pm 1,132$ & $53,510 \pm 968$ (NS) \\
\hline 11 & $6.3 \pm 0.11$ & $6.1 \pm 0.09(\mathrm{NS})$ & $4,700 \pm 68$ & $4,636 \pm 56(\mathrm{NS})$ & $74,691 \pm 844$ & $75,068 \pm 967$ (NS) \\
\hline 12 & $3.5 \pm 0.08$ & $3.2 \pm 0.09^{*}$ & $3,116 \pm 47$ & $2,857 \pm 115^{*}$ & $88,352 \pm 632$ & $88,334 \pm 1,944$ (NS) \\
\hline 13 & $5.2 \pm 0.14$ & $4.9 \pm 0.11^{*}$ & $2,182 \pm 63$ & $1,939 \pm 50 *$ & $41,683 \pm 1,246$ & $39,808 \pm 1,023(\mathrm{NS})$ \\
\hline 14 & $10.2 \pm 0.16$ & $9.6 \pm 0.12^{*}$ & $4,890 \pm 35$ & $4,664 \pm 56^{*}$ & $47,769 \pm 583$ & $48,788 \pm 821(\mathrm{NS})$ \\
\hline 15 & $4.0 \pm 0.08$ & $3.7 \pm 0.06^{*}$ & $1,910 \pm 40$ & $1,790 \pm 53$ & $47,178 \pm 796$ & $48,241 \pm 685(\mathrm{NS})$ \\
\hline 16 & $10.2 \pm 0.24$ & $9.6 \pm 0.30^{*}$ & $2,194 \pm 23$ & $2,015 \pm 15^{*}$ & $21,429 \pm 361$ & $21,872 \pm 405$ (NS) \\
\hline 17 & $10.6 \pm 0.21$ & $10.2 \pm 0.10^{*}$ & $7,794 \pm 196$ & $7,472 \pm 116^{*}$ & $73,275 \pm 252$ & $73,158 \pm 388$ (NS) \\
\hline 18 & $11.2 \pm 0.44$ & $10.6 \pm 0.25^{*}$ & $822 \pm 32$ & $736 \pm 26^{*}$ & $7,293 \pm 197$ & $7,021 \pm 208(\mathrm{NS})$ \\
\hline 19 & $11.1 \pm 0.36$ & $10.0 \pm 0.48 \ddagger$ & $2,097 \pm 67$ & $1,845 \pm 86 \ddagger$ & $18,865 \pm 168$ & $19,073 \pm 142$ (NS) \\
\hline 20 & $5.4 \pm 0.32$ & $4.7 \pm 0.29^{*}$ & $2,281 \pm 50$ & $2,168 \pm 24^{*}$ & $42,351 \pm 1,769$ & $45,330 \pm 2,054(\mathrm{NS})$ \\
\hline 21 & $2.5 \pm 0.06$ & $2.3 \pm 0.04^{*}$ & $2,807 \pm 48$ & $2,495 \pm 50^{*}$ & $114,754 \pm 3,991$ & $106,138 \pm 3,262^{*}$ \\
\hline 22 & $16.3 \pm 0.43$ & $16.1 \pm 0.39(\mathrm{NS})$ & $11,827 \pm 263$ & $11,667 \pm 218(\mathrm{NS})$ & $72,561 \pm 1,358$ & $72,875 \pm 984(\mathrm{NS})$ \\
\hline 23 & $6.0 \pm 0.29$ & $5.7 \pm 0.21(\mathrm{NS})$ & $9,771 \pm 128$ & $9,329 \pm 269^{*}$ & $151,960 \pm 3,656$ & $162,596 \pm 4,931^{*}$ \\
\hline 24 & $5.6 \pm 0.41$ & $5.4 \pm 0.50(\mathrm{NS})$ & $2,080 \pm 30$ & $1,985 \pm 13^{*}$ & $36,932 \pm 1,728$ & $36,789 \pm 2,051(\mathrm{NS})$ \\
\hline 25 & $2.7 \pm 0.06$ & $2.5 \pm 0.03^{*}$ & $3,504 \pm 66$ & $3,381 \pm 97(\mathrm{NS})$ & $128,112 \pm 2,547$ & $132,588 \pm 3,866(\mathrm{NS})$ \\
\hline 26 & $7.5 \pm 0.39$ & $6.8 \pm 0.34^{*}$ & $2,120 \pm 53$ & $2,001 \pm 46^{*}$ & $28,126 \pm 1,843$ & $30,164 \pm 1,327(\mathrm{NS})$ \\
\hline 27 & $5.2 \pm 0.11$ & $4.9 \pm 0.17^{*}$ & $7,427 \pm 146$ & $7,091 \pm 132 *$ & $145,036 \pm 8,219$ & $145,703 \pm 7,961$ (NS) \\
\hline 28 & $3.5 \pm 0.18$ & $3.2 \pm 0.11^{*}$ & $2,758 \pm 37$ & $2,687 \pm 60$ (NS) & $75,550 \pm 2,843$ & $82,360 \pm 3,115^{*}$ \\
\hline 29 & $8.0 \pm 0.24$ & $7.8 \pm 0.43(\mathrm{NS})$ & $3,784 \pm 30$ & $3,629 \pm 38$ (NS) & $46,667 \pm 1,547$ & $46,339 \pm 2,159(\mathrm{NS})$ \\
\hline
\end{tabular}

Results are given as mean \pm SEM of 24 measurements. Statistical comparisons of arterial and hepatic venous data were performed by Student's $t$ test: ${ }^{*} P<0.05 ; \$ P<0.01 ;$ NS, $P>0.05$.

The segregation of the patients corresponds to the three protocols used (see Table I).

$5 \mathrm{~h}$ of infusion, averaging $55 \%$ beyond this time (range, 41-67\%). For technical reasons splanchnic plasma flow was not measured in these patients. Using the mean flow obtained in studies 1-19, their absolute rates of conversion of Sf 12-60 apo B to Sf 0-12 apo B averaged $1.07 \mathrm{mg} / \mathrm{kg}$ per $\mathrm{h}$ (range, $0.56-2.52$ ). Two patients with Type III hyperlipoproteinemia showed much lower fractional rates of conversion (Fig. 1).

Sf 0-12 lipoproteins. In no patient was there a statistically significant difference between the arterial and hepatic vein concentrations of Sf 0-12 apo B (Table IV), although in the pooled data there was a trend for the mean concentrations to be greater in the hepatic vein than in the artery (paired $t$ test: $0.05<P<0.10$ ). There was no detectable uptake of ${ }^{131} \mathrm{I}$-apo $\mathrm{B}$ by the splanchnic organs when ${ }^{131}$ I-labeled Sf 0-12 lipoproteins were in- jected intravenously $5 \mathrm{~h}$ before blood sampling (Table IV).

\section{DISCUSSION}

In these studies radioiodinated apo $B$ was used as a marker of the metabolism of Sf 0-400 lipoproteins. There is good evidence to support the validity of this approach. Unlike other lipoprotein components, apo B is quantitatively conserved during the conversion of VLDL via IDL to $\operatorname{LDL}(4,33)$. Secondly, following intravenous injection of radioiodinated LDL no significant transfer of apo $\mathrm{B}$ radioactivity occurs to less dense lipoproteins (26). Thirdly, lipolysis of VLDL triglyceride in vitro results in the quantitative transfer of apo B to LDL-like particles (34). 
TABLE IV

Sf 0-12 Apoprotein B Mass, Radioactivity, and Specific Activity in Arterial and Hepatic Venous Plasma following Intravenous Injection of ${ }^{125}$ I-labeled Sf 12-60 Lipoproteins and ${ }^{131}$ I-labeled Sf 0-12 Lipoproteins

\begin{tabular}{|c|c|c|c|c|c|c|c|c|}
\hline \multirow{2}{*}{$\begin{array}{c}\text { Patient } \\
\text { No. }\end{array}$} & \multicolumn{2}{|c|}{ Mass } & \multicolumn{2}{|c|}{${ }^{131}$ I Radioactivity } & \multicolumn{2}{|c|}{${ }^{131}$ I Specific activity } & \multicolumn{2}{|c|}{ 125I Radioactivity } \\
\hline & Artery & Hepatic vein & Artery & Hepatic vein & Artery & Hepatic vein & Artery & Hepatic vein \\
\hline & \multicolumn{2}{|c|}{$m g / d l$} & \multicolumn{2}{|c|}{$c p m / m l$} & \multicolumn{2}{|c|}{$c p m / m g$} & \multicolumn{2}{|c|}{$c p m / m l$} \\
\hline 13 & $72.5 \pm 6.63$ & $78.8 \pm 7.20$ (NS) & $3,470 \pm 51$ & $3,557 \pm 80(\mathrm{NS})$ & $4,772 \pm 363$ & $4,629 \pm 347$ (NS) & $275 \pm 11$ & $320 \pm 34^{*}$ \\
\hline 14 & $105.6 \pm 4.91$ & $109.2 \pm 4.71$ (NS) & $412 \pm 7$ & $417 \pm 6$ (NS) & $401 \pm 61$ & $388 \pm 48$ (NS) & $51 \pm 8$ & $57 \pm 12(\mathrm{NS})$ \\
\hline 15 & $70.0 \pm 3.40$ & $71.9 \pm 2.80(\mathrm{NS})$ & $789 \pm 23$ & $773 \pm 18(\mathrm{NS})$ & $1,114 \pm 206$ & $1,094 \pm 231(\mathrm{NS})$ & $144 \pm 12$ & $171 \pm 20^{*}$ \\
\hline 16 & $110.5 \pm 6.74$ & $118.9 \pm 5.21(\mathrm{NS})$ & $437 \pm 26$ & $451 \pm 16(\mathrm{NS})$ & $387 \pm 47$ & $391 \pm 65$ (NS) & $166 \pm 17$ & $193 \pm 14^{*}$ \\
\hline 17 & $97.5 \pm 4.10$ & $97.3 \pm 3.81(\mathrm{NS})$ & $439 \pm 17$ & $446 \pm 28(\mathrm{NS})$ & $441 \pm 54$ & $457 \pm 63$ (NS) & $1,746 \pm 17$ & $1,854 \pm 27^{*}$ \\
\hline 18 & $88.1 \pm 5.22$ & $92.6 \pm 6.47(\mathrm{NS})$ & $822 \pm 32$ & $874 \pm 26$ (NS) & $946 \pm 73$ & $932 \pm 56$ (NS) & $273 \pm 20$ & $314 \pm 13^{*}$ \\
\hline 19 & $83.5 \pm 4.63$ & $78.6 \pm 4.45$ (NS) & $307 \pm 15$ & $312 \pm 8$ (NS) & $388 \pm 24$ & $399 \pm 53$ (NS) & $910 \pm 22$ & $1,044 \pm 48^{*}$ \\
\hline 20 & $96.8 \pm 5.83$ & $90.4 \pm 4.74$ (NS) & & & & & $1,018 \pm 21$ & $1,066 \pm 18^{*}$ \\
\hline 21 & $94.5 \pm 3.39$ & $93.4 \pm 2.92(\mathrm{NS})$ & & & & & $1,184 \pm 29$ & $1,389 \pm 60^{*}$ \\
\hline 22 & $67.5 \pm 2.18$ & $69.1 \pm 3.41(\mathrm{NS})$ & & & & & $4,025 \pm 138$ & $4,039 \pm 121(\mathrm{NS})$ \\
\hline 23 & $94.8 \pm 5.07$ & $95.3 \pm 4.91$ (NS) & & & & & $7,528 \pm 64$ & $7,731 \pm 90^{*}$ \\
\hline 24 & $71.4 \pm 5.42$ & $75.3 \pm 4.71(\mathrm{NS})$ & & & & & $4,923 \pm 56$ & $4,977 \pm 49(\mathrm{NS})$ \\
\hline 25 & $57.1 \pm 2.90$ & $57.9 \pm 3.62(\mathrm{NS})$ & & & & & $994 \pm 28$ & $1,058 \pm 19^{*}$ \\
\hline 26 & $94.0 \pm 3.79$ & $96.2 \pm 4.11$ (NS) & & & & & $1,083 \pm 24$ & $1,164 \pm 32^{*}$ \\
\hline 27 & $55.7 \pm 4.15$ & $57.7 \pm 6.61(\mathrm{NS})$ & & & & & $2,630 \pm 48$ & $2,803 \pm 67^{*}$ \\
\hline 28 & $106.5 \pm 4.79$ & $108.1 \pm 3.88(\mathrm{NS})$ & & & & & $3,947 \pm 23$ & $3,986 \pm 19^{*}$ \\
\hline 29 & $82.3 \pm 6.12$ & $80.0 \pm 5.80$ (NS) & & & & & $3,137 \pm 38$ & $3,157 \pm 51(\mathrm{NS})$ \\
\hline
\end{tabular}

Subjects 20-29 received ${ }^{125}$ I-labeled Sf 12-60 lipoproteins only (protocol 3); subjects 13-19 were given both isotopes (protocol 2). Results are given as mean \pm SEM of 24 measurements. Statistical comparisons of arterial and hepatic venous data were performed by Student's $t$ test: ${ }^{*} P<0.05 ; \mathrm{NS}, P>0.05$.

A second assumption was that the measurements were made under steady-state conditions. To this end the patients spent several days in a metabolic ward prior to catheterization, so as to ensure constancy of energy balance and dietary composition, and all studies were conducted in the fasted state. During the

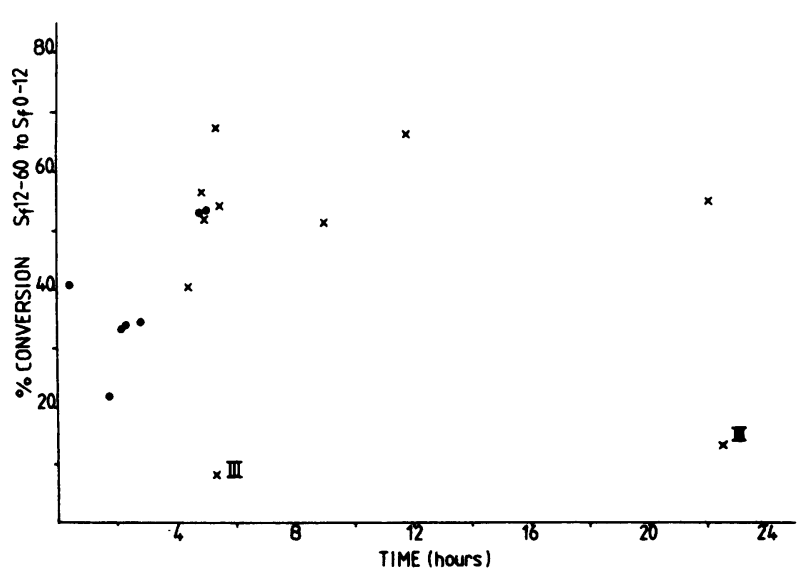

FIgURE 1 Percentage conversion by splanchnic tissues of extracted Sf $12-60$ apo B to Sf 0-12 apo B. Values on the horizontal axis are the time intervals between intravenous bolus injection $(O)$ or commencement of a continuous intravenous infusion $(x)$ of radioiodinated Sf 12-60 lipoproteins and blood sampling. The two Type III hyperlipoproteinemic patients are indicated. precatheterization period body weights remained essentially constant.

The results showed that newly synthesized apo B is secreted by splanchnic tissues as a component of $\mathrm{Sf}$ 100-400 lipoproteins in man. Using similar techniques, net secretion of triglyceride by human splanchnic viscera has been demonstrated $(13,14)$, and VLDL production by the perfused rat liver $(17,35,36)$ is well documented. No splanchnic uptake of Sf 100-400 apo B could be detected in any of the patients studied, on the basis of either mass or radioactivity measurements. It remains possible, however, that some Sf $100-400$ triglyceride was hydrolyzed by splanchnic tissues without producing a detectable shift of ${ }^{131}$ I-apo B to $S f<100$ lipoproteins.

In contrast to the results obtained for Sf 100-400 lipoproteins, no splanchnic secretion of apo B in Sf 12-60 lipoproteins could be detected. This finding is compatible with the evidence from kinetic studies that it is the VLDL subclasses of greatest flotation rate that are the primary secreted forms, the smaller more dense subclasses being largely catabolic products $(3,4,37)$. The results of in vitro studies, in which the hydrolysis of VLDL triglyceride by lipoprotein lipase has been shown to generate progressively smaller and denser particles $(34,38)$, have supported this concept.

On the basis of the known composition of VLDL (24), the artery-hepatic vein differences in Sf 100-400 apo B concentration were in agreement with those in VLDL 
cholesterol concentration reported by Sniderman et al. (15). The calculated splanchnic secretion rates of Sf $100-400$ apo $B$ in the fasted state were also compatible with the rates of splanchnic triglyceride secretion obtained by Boberg et al. (14) by measurement of arteryhepatic vein differences in triglyceride concentration under similar experimental conditions. Our secretion rates of apo $B$ exceeded, however, the rates of VLDL apo $B$ synthesis in the fed state (low-fat diets) previously obtained in this and other laboratories by kinetic analysis of plasma apo B specific activity decay curves after intravenous injection of radiolabeled VLDL (3-9). This suggests that there may be a diurnal variation in the hepatic production of VLDL apo B in man, perhaps in response to the documented diurnal variation in plasma free fatty acid concentrations (39). It is also possible that there is some recycling of apo B, derived from extracted $\mathrm{Sf}>100$ particles, into new Sf 100-400 lipoproteins by the liver.

Another notable aspect of this study was the demonstration that the human splanchnic organs extract $S f 12-$ 60 lipoproteins from the circulation. The role of the liver in the uptake of VLDL "remnants" (19) and chylomicron remnants (18) in the rat is well documented, but there is no published evidence for a similar process in man. The rates of splanchnic Sf 12-60 apo B extraction in eight normotriglyceridemic patients were lower $(P<0.05)$ than the rates of Sf $100-400$ apo B secretion, suggesting that there was some extrasplanchnic catabolism of VLDL particles not resulting in their conversion to Sf $12-60$ lipoproteins. The reason for the discrepancy between this result and the evidence from kinetic studies for the quantitative transfer of apo B from VLDL to Sf 0-20 lipoproteins in normotriglyceridemic individuals $(2,4)$ is not clear, but may be related to the differing experimental conditions under which the measurements were made.

Our results also indicated that a proportion of the Sf 12-60 lipoproteins extracted by the human splanchnic bed is converted to Sf 0-12 lipoproteins. The percentage transfer of extracted Sf $12-60$ radioactivity to hepatic vein Sf 0-12 lipoproteins increased in curvilinear manner with increasing time interval between the injection of radiolabeled $\mathrm{Sf} 12-60$ and blood sampling, perhaps reflecting the presence of a slowly turning-over intermediate pool in the splanchnic tissues. The greatest conversion rates, observed after continuous intravenous infusion of radiolabel for 5-22 $\mathrm{h}$, averaged $55 \%$.

Our measurements failed to detect any splanchnic extraction of Sf 0-12 lipoproteins. Evidence obtained from tissue culture (40) and animal experiments (41) suggests that LDL is catabolized partly in the liver and partly in extrahepatic tissues. Although our findings do not support a role of the liver in LDL catabolism, they do not exclude this possibility: artery-hepatic vein dif- ferences in radioactivity too small to be demonstrated by the procedure used for isolating Sf $0-12$ apo B could nevertheless be physiologically significant.

\section{ACKNOWLEDGMENTS}

This work was supported by grants from the Medical Research Council (England) and the Research Endowments Committee of St. Thomas' Hospital.

\section{REFERENCES}

1. Eisenberg, S., D. W. Bilheimer, R. I. Levy, and F. T. Lindgren. 1973. On the metabolic conversion of human plasma very low density lipoprotein to low density lipoprotein. Biochim. Biophys. Acta. 326: 361-377.

2. Sigurdsson, G., A. Nicoll, and B. Lewis. 1975. Conversion of very low density lipoprotein to low density lipoprotein. A metabolic study of apolipoprotein B kinetics in human subjects. J. Clin. Invest. 56: 1481-1490.

3. Reardon, M. F., N. H. Fidge, and P. J. Nestel. 1978. Catabolism of very low density lipoprotein B apoprotein in man. J. Clin. Invest. 61: 850-860.

4. Berman, M., M. Hall, R. I. Levy, S. Eisenberg, D. W. Bilheimer, R. D. Phair, and R. H. Goebel. 1978. Metabolism of apo $B$ and apo $C$ lipoproteins in man: kinetic studies in normals and in hyperlipoproteinemics. J. Lipid Res. 19: 38-56.

5. Janus, E. D., A. Nicoll, R. Wootton, P. R. Turner, P. J. Magill, and B. Lewis. 1980. Quantitative studies of very low density lipoprotein conversion to low density lipoprotein in normal controls and primary hyperlipidaemic states and the role of direct secretion of low density lipoprotein in heterozygous familial hypercholesterolaemia. Eur. J. Clin. Invest. 10: 149-159.

6. Soutar, A. V., N. B. Myant, and G. R. Thompson. 1977. Simultaneous measurement of VLDL-apoB and LDLapoB synthesis in familial hypercholesterolaemia. In Proceedings XXVth Symposium: Protides of the Biological Fluids. 175-178.

7. Janus, E. D., A. M. Nicoll, P. R. Turner, P. Magill, and B. Lewis. 1980. Kinetic bases of the primary hyperlipidaemias: studies of apolipoprotein B turnover in genetically defined subjects. Eur. J. Clin. Invest. 10: 161-172.

8. Sigurdsson, G, A. Nicoll, and B. Lewis. 1976. Metabolism of very low density lipoprotein in hyperlipidaemia: studies of apolipoprotein B kinetics in man. Eur. J. Clin. Invest. 6: 167-177.

9. Chait, A., J. J. Albers, and J. D. Brunzell. 1980. Very low density lipoprotein overproduction in genetic forms of hypertriglyceridaemia. Eur. J. Clin. Invest. 10: 17-22.

10. Quarfordt, S. H., A. Frank, D. M. Shames, M. Berman, and D. Steinberg. 1970. Very low density lipoprotein triglyceride transport in Type IV hyperlipoproteinemia and the effects of carbohydrate-rich diets. J. Clin. Invest. 49: 2281-2297.

11. Volwiler, W. P., P. D. Goldsworthy, M. P. MacMartin, P. A. Wood, I. R. Mackey, and G. Fremont-Smith. 1955. Biosynthetic determination with radioactive sulfur of turnover rates of various plasma proteins in normal and cirrhotic man. J. Clin. Invest. 34: 1126-1141.

12. Hammond, M. G., and W. R. Fisher. 1971. The characterization of a discrete series of low density lipoproteins in the disease, hyper-pre-beta lipoproteinemia. Implication relating to the structure of plasma lipoproteins. J. Biol. Chem. 246: 5454-5465. 
13. Havel, R. J., J. P. Kane, E. O. Balasse, N. Segel, and L. V. Basso. 1970. Splanchnic metabolism of free fatty acids and production of triglycerides of very low density lipoproteins in normotriglyceridemic and hypertriglyceridemic humans. J. Clin. Invest. 49: 2017-2035.

14. Boberg, J., L. A. Carlson, V. Freyschuss, B. W. Lassers, and M. L. Wahlqvist. 1972. Splanchnic secretion rates of plasma triglycerides and total and splanchnic turnover of plasma free fatty acids in men with normo and hypertriglyceridaemia. Eur. J. Clin. Invest. 2: 454-466.

15. Sniderman, A., D. Thomas, D. Marpole, and B. Teng. 1978. Low density lipoprotein. A metabolic pathway for return of cholesterol to the splanchnic bed.J. Clin. Invest. 61: 867-873.

16. Quarfordt, S. H., and D. S. Goodman. 1969. Chylomicron cholesteryl ester metabolism in the perfused rat liver. Biochim. Biophys. Acta. 176: 863-872.

17. Noel, S. P., and D. Rubinstein. 1974. Secretion of apolipoproteins in very low density and high density lipoproteins by perfused rat liver. J. Lipid Res. 15: 301-308.

18. Redgrave, T. G. 1970. Formation of cholesteryl ester-rich particulate lipid during metabolism of chylomicrons. J. Clin. Invest. 49: 465-471.

19. Mjøs, O. D., O. Faergeman, R. L. Hamilton, and R. J. Havel. 1975. Characterization of remnants produced during the metabolism of triglyceride-rich lipoproteins of blood plasma and intestinal lymph in the rat. J. Clin. Invest. 56: 603-615.

20. Bergman, E. N., R. J. Havel, B. M. Wolfe, and T. Bøhmer. 1971. Quantitative studies of the metabolism of chylomicron triglycerides and cholesterol by liver and extrahepatic tissues of sheep and dogs. J. Clin. Invest. 50: $1831-1839$.

21. Eisenberg, S., and D. Rachmilewitz. 1973. Metabolism of rat plasma very low density lipoprotein. I. Fate in circulation of the whole lipoprotein. Biochim. Biophys. Acta. 326: 378-390.

22. Beaumont, J. L., L. A. Carlson, G. R. Cooper, Z. Fejfar, D. S Fredrickson, and T. Strasser. 1970. Classification of hyperlipidaemias and hyperlipoproteinaemias. Bull.W. H. O. 43: 891-915.

23. Havel, R. J., H. A. Eder, and J. H. Bragdon. 1955. The distribution and chemical composition of ultracentrifugally separated lipoproteins in human serum. J. Clin. Invest. 34: 1345-1353.

24. Gustafson, A., P. Alaupovic, and R. H. Furman. 1965 Studies of the composition and structure of serum lipoproteins: isolation, purification, and characterization of very low density lipoproteins of human serum. Biochemistry. 4: 596-605.

25. McFarlane, A. S. 1958. Efficient trace-labelling of proteins with iodine. Nature (Lond.). 182: 53.

26. Langer, T., W. Strober, and R. I. Levy. 1972. The metabolism of low density lipoprotein in familial Type II hyperlipoproteinemia. J. Clin. Invest. 51: 1528-1536.
27. Scanu, A. M., and C. Edelstein. 1971. Solubility in aqueous solution of ethanol of the small molecular weight peptides of the serum very low density and high density lipoproteins. Anal. Biochem. 44: 576-588.

28. Seldinger, S. I. 1953. Catheter replacement of the needle in percutaneous arteriography. A new technique. Acta Radiol. 39: 368-376.

29. Porte, D. Jr., and E. L. Bierman. 1969. The effect of heparin infusion on plasma triglyceride in vivo and in vitro with a method for calculating triglyceride turnover. J. Lab. Clin. Med. 73: 631-648.

30. Rowell, L. B., J. R. Blackmon, and R. A. Bruce. 1964. Indocyanine green clearance and estimated hepatic blood flow during mild to maximal exercise in upright man. $J$. Clin. Invest. 43: 1677-1690.

31. Kane, J. P., T. Sata, R. L. Hamilton, and R. J. Havel. 1975. Apoprotein composition of very low density lipoproteins of human serum. J. Clin. Invest. 56: 1622-1634.

32. Lowry, O. H., N. J. Rosebrough, A. L. Farr, and R. J. Randall. 1951. Protein measurement with the Folin phenol reagent. J. Biol. Chem. 193: 265-275.

33. Schaefer, E. J., S. Eisenberg, and R. I. Levy. 1978. Lipoprotein apoportein metabolism. J. Lipid Res. 19: 667687.

34. Deckelbaum, R., S. Eisenberg, Y. Barenholz, and T. Olivecrona. 1977. Production of human low density lipoprotein-like ("LDL") particles in vitro. Circulation. 56: III-56 (Abstr.)

35. Suri, B. S., M. E. Targ, and D. S. Robinson. 1979. The metabolic conversion of very-low-density lipoprotein into low-density lipoprotein by the extrahepatic tissues of the rat. Biochem. J. 178: 455-466.

36. Windmueller, H. G., P. N. Herbert, and R. I. Levy. 1973. Biosynthesis of lymph and plasma lipoprotein apoprotein by isolated perfused rat liver and intestine. J. Lipid Res. 14: 215-223.

37. Barter, P. J., and P. J. Nestel. 1972. Precursor-product relationship between pools of very low density lipoprotein triglyceride. J. Clin. Invest. 51: 174-180.

38. Eisenberg, S., and D. Rachmilewitz. 1975. Interaction of rat plasma very low density lipoprotein with lipoprotein lipase-rich (post-heparin) plasma. J. Lipid Res. 16: 341-351.

39. Schlierf, G., and H. Raetzer. 1972. Diurnal patterns of blood sugar, plasma insulin, free fatty acid and triglyceride levels in normal subjects and in patients with type IV hyperlipoproteinemia and the effect of meal frequency. Nutr. Metab. 14: 113-126.

40. Goldstein, J. L., and M. S. Brown. 1977. The low density receptor hypothesis. Metab. Clin. Exp. 26: 1257-1275.

41. Pittman, R. C., A. D. Attie, T. E. Carew, and D. Steinberg. 1979. Tissue sites of degradation of low density lipoprotein: Application of a method for determining the fate of plasma proteins. Proc. Natl. Acad. Sci. U. S. A. 76: 5345-5349. 